\author{
EISSN:2706-7920 ISSN: 2077-4435 \\ DOI: $10.36632 / \mathrm{csi} / 2021.10 .4 .54$ \\ Journal homepage: www.curresweb.com \\ Pages: 644-657
}

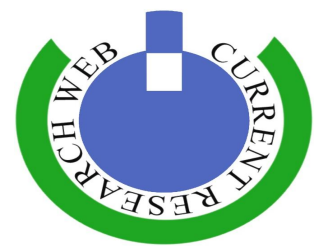

\title{
Molecular Characterization of Sugarcane Mosaic Virus and its Influence on Sugarcane Yield and Juice Quality
}

\author{
Hala A. Amin', Mohamed A.M. Osman² and Samah A. Mokbel ${ }^{1}$
}

\author{
${ }^{I}$ Virus and Phytoplasma Research Department, Plant Pathology Research Institute, Agricultural \\ Research Center (ARC), P.O. Box 12619, Giza, Egypt. \\ ${ }^{2}$ Plant Pathology and Entomology, Sugar Crops Research Institute, ARC, Giza, Egypt.
}

Received: 18 Oct. $2021 \quad$ Accepted: 12 Nov. $2021 \quad$ Published: 20 Nov. 2021

\begin{abstract}
In 2018, mosaic symptoms were observed on sugarcane plantations of the commercial variety G.T. 54-9 that grown at Qena governorate, Egypt. The initial serological diagnosis confirmed that the Sugarcane mosaic virus (SCMV) was the causative agent of mosaic disease on sugarcane. Mosaic correlation with the altered photosynthetic activity caused a significant reduction for chlorophyll content by 56\%, and 40\% through the tested experimental seasons 2018/2019 and 2019/2020, respectively. The decrease in chlorophyll content led to a reduction in various growth parameters in sugarcane variety G.T. 54-9, such as stalk length and diameter, the number of internodes per plant, cane yield, and cane stalk juice quality through both experimental seasons. Concerning the reducing sugars (Rs), the concentration increased in infected sugarcane plants with SCMV in both tested seasons by $9.7 \%$ and $4.7 \%$, respectively. Leaves from Sugarcane plants tested positive in a reverse transcription-PCR using SCMV-specific primers for coat protein gene. All tested plants are from vegetative cuttings of the original infected plant which show mosaic symptoms with different severity. All samples showed an expected band at about $900 \mathrm{bp}$. The PCR amplicon of the CP gene was analyzed by nucleotide sequence analysis. The coat protein sequence comparison revealed that the current SCMV isolate (HaF isolate) shared the highest nucleotide identity (97.9-100\%) with the Egyptian isolate EGY7-1 and with all Iranian GenBank reference isolates. The phylogenetic analysis showed that the HaF isolate grouped in a clade with the EGY7-1 and KhuzM isolates and it closely related to KhuzM isolate from Iran. The coat protein core region (CP-CR) of the Egyptian SCMV $(\mathrm{HaF})$ isolate shared 98\% sequence homology with SCMV-E serotype strain from the USA and the current $\mathrm{HaF}$ Egyptian isolate contains a conserved DAG motif in its $\mathrm{N}$-terminal region in CP sequence which is associated with aphid transmissibility. An SCMV-infected Sugarcane crop could pose a threat to established crops of Sorghum, Maize, and many susceptible sugarcane varieties in Upper Egypt since the virus can spread non-persistently by aphid species as well as by planting infected cane cuttings.
\end{abstract}

Keywords: Sugarcane, Sugarcane mosaic virus (SCMV), Potyvirus, Sugarcane quality, RT-PCR, Sequencing, Coat protein core region (CP-CR)

\section{Introduction}

Sugarcane, (Saccharum officinarum) is one of the summer field crops in Egypt, belonging to the tall perennial grasses that reach 3 to 7 meters (10 to 24 feet) high, in the genus Saccharum of the family Poaceae. It is the major source of sugar for human consumption, and an important source of ethanol for biofuel (Boddey et al., 2008; Tang et al., 2018). Egypt produces 15242687 tons of sugarcane in an area of 136915 hectares (FAOSTAT, 2019).

Corresponding Author: Samah A. Mokbel, Virus and Phytoplasma Research Department, Plant Pathology Research Institute, Agricultural Research Center (ARC), P.O. Box 12619, Giza, Egypt. E-mail: samah.mokbel@arc.sci.eg Orcid ID https://orcid.org/0000-0001-9374-9552 
The mosaic disease is the most disease that severely compromises the stalk yield and sucrose content of sugarcane in the field. Mosaic-like symptoms spread over the entire leaf surface and are present with various possible causative agents, including nutrient deficiency and plant viruses (Rao et al., 2006). Among viral pathogens, the Sugarcane mosaic virus (SCMV) is the most prevalent one in many countries around the world (Tang et al., 2018). In Egypt, SCMV, the most dangerous virus for economically important sugarcane crops either alone or in combination with other viruses, and one of the species of the genus Potyvirus in the Potyviridae family that transmitted by aphids in a nonpersistent manner (Abd El Fattah et al., 2004; 2005). The symptoms caused by plant viruses such as Sugarcane streak mosaic virus (SCSMV), Sorghum mosaic virus (SrMV), Maize dwarf mosaic (MDMV), and SCMV are the most difficult to distinguish by morphological observations alone. Therefore, it is necessary to accurately identify the causative agent of mosaic on sugarcane through molecular assay. The SCMV has flexuous filamentous particles, 700 750 nm long, and 11-13 nm wide, with helical symmetry. The SCMV genome is single-stranded, positive RNA containing a single open reading frame (ORF), which codes a large polyprotein and a truncated frameshift product (Chung et al., 2008). The SCMV isolates can be clustered into four groups according to the phylogenetic analysis of the complete genomic sequences. However, according to the phylogenetic results of coat protein genes, SCMV isolates are divided into five groups (A to E) specific to host origins (Gao et al., 2011). The population of SCMV isolates from infected sugarcane plants in Africa including Egypt contains virus genotypes that had not yet been described and identified.

The chlorophyll content is crucial for agriculture, in which it is important to detect crop stress, photosynthetic capacity, and nutritional status (Jiang et al., 2010; Xu et al., 2015). Moreover, the sugarcane variety is one of the main factors in controlling the expected sugar yield. Many studies were carried out to evaluate sugarcane varieties such as G.T.54-9, Phil.8013, G.95-21, G.99-165, G.98-28, and G.95-19 for productivity and quality parameters under different agricultural treatments. The cultivar G.T.54-9 has widely been used in all producing regions in Upper Egypt and showed superiority over the other varieties in stalk length, the number of millable cane $/ \mathrm{m}^{2}$, juice purity, sugar recovery rate, sucrose percentage, and top yield/feddan, compared with other tested varieties (Ismail et al., 2008; El-Sogheir and Abd El Fattah, 2009; Ahmed et al., 2014).

The present study was aimed to characterize the SCMV at the molecular level that causes mosaic disease on sugarcane (cv. G.T. 54-9) variety in Upper Egypt. A study was also conducted to describe the SCMV type strain and its effect on growth parameters and juice quality on sugarcane (cv. G.T. 54-9) variety.

\section{Materials and Methods}

\section{Plant material and serological detection}

Eighty leaf samples taken from 80 sugarcane-stalk tips comprising the commercial variety (G.T. 54-9) exhibiting viral infection were collected from Qus, Abu Tesht, and Nag Hammadi centers in Qena governorate in 2018. The observed symptoms included severe mosaic, chlorotic streaks, and reddish necrotic streaks on leaves. The collected samples were labelled, brought to the laboratory in an icebox, and stored at a temperature of $4^{\circ} \mathrm{C}$. Enzyme-linked immune-sorbent assays, I-ELISA and DAS-ELISA, were conducted to test the samples against SCMV and SCSMV according to Koenig and Paul (1982), and Clark and Adams (1977), respectively. Agdia (USA) and LOEWE Biochemica GmbH (Germany) supplied ELISA kits (specific antisera). Samples were considered positive if the absorbance values at $405 \mathrm{~nm}$, using an ELISA microplate reader (Dynatech MR 7000), were higher than twice the absorbance of the negative controls. Commercial positive and negative controls were included in each ELISA test. I-ELISA results confirmed the presence of SCMV in all tested samples, while DAS-ELISA tests did not detect SCSMV in such samples.

\section{Plant material and experimental design}

The purpose of the experiment was to determine the effect of SCMV on plant growth and the juice quality of sugarcane. The commercial sugarcane G.T. 54-9 variety was used. A field experiment was conducted during two successive seasons 2018/2019 and 2019/2020 at the farm of El-Mattana Research Station, Luxor Governorate, which is a separate area prepared for disease experiments. The experimental unit area was $77 \mathrm{~m} 2,7 \mathrm{~m}$ in length, and $11 \mathrm{~m}$ in width. The experimental unit contained 
three plots and each plot contained three subplots of 3 rows and $100 \mathrm{~cm}$ between rows and $1 \mathrm{~m}$ apart between plots. A randomized complete block design was used with three replications during the first week of March in both seasons. The accessions were randomized in three rows of 138 cuttings (consisted of 414 buds) in which 46 cuttings (duple of three buds) were randomized in each row, in 7 meters in length. The cuttings from the plant stalks per row originated from either SCMV-infected (positive ELISA results) or SCMV-free cuttings. The healthy cuttings from the same variety were obtained from 11-month-old cane fields from the El-Mattana Research Station farm for planting as control plants. The experimental plots were irrigated after planting and every two weeks. All sugarcane managements (in the field), including pest, weed, and disease control, and potassium and phosphate fertilizers, were applied. The recommended doses of NPK at rates of $230 \mathrm{~kg} \mathrm{~N} / \mathrm{fed}, 60 \mathrm{~kg}$ $\mathrm{P}_{2} \mathrm{O}_{5}$, and $48 \mathrm{~kg} \mathrm{~K} \mathrm{~K}_{2} \mathrm{O} / \mathrm{fed}$, were used. The top visible dewlap leaf was used for SCMV-detection in plants 11 months after planting in both tested seasons (2018-2019 and 2019-2020) with the use of reverse transcription-polymerase chain reaction (RT-PCR) assay as described later.

\section{Measured parameters and traits}

Growth data were determined pre-harvest in both seasons. For the measurement, were selected randomly stalks from each season and was calculated the average. The length of the stalks from soil level to the visible dewlap, their diameter at the middle, and the number of internodes per plant were measured. Cane yield (tons/fed) from each plot was harvested, topped, cleaned, weighed, and then net cane yield was calculated. Chlorophyll contents in sugarcane leaves were analyzed using a chlorophyll meter (SPAD-502, Germany).

\section{Juice quality analysis}

Stripped stalk samples were immediately crushed through an electric pilot mill; the raw juice was filtered and used to determine the following characters: Sucrose percentage, Polarization (Pol) percentage, Reducing sugars (Rs), and Apparent purity (Ap) percentages, according to the methods of Meade and Chen (1977).

Brix percentage represents the present percentage of Total Soluble Solids (TSS or Bx) in juice, which was determined using a method described by Plews (1970), using a Brix hydrometer.

Sugar recovery percentage and Sugar yield (ton/fed) were calculated according to the formulas described by Yadav and Sharma (1980):

Sugar recovery $\%=[S-0.4(B-S)] \times 0.73$

Where: $\mathrm{B}=$ Brix reading, $\mathrm{S}=$ Sucrose percentage, 0.4 and 0.73 constants.

Sugar yield $($ ton $/$ fed $)=$ net cane yield $($ ton $/$ fed $) \times$ sugar recovery percentage.

\section{Statistical analysis}

The percentage of data was transformed by Arc-sin logarithmic before statistical analysis. Statistical analysis according to the technique of analysis of variance (ANOVA) as published by Gomez and Gomez (1984), using the computer MSTAT.C statistical analysis package by Freed et al., (1989). The Least Significant Difference (LSD) method was used to test the differences between means at a $5 \%$ level of probability.

\section{RNA extraction and reverse transcription-polymerase chain reaction (RT-PCR)}

Leaves of sugarcane stalks with/without mosaic symptoms during the periods of vegetative growth were collected from the tested seasons, 2018-2019 and 2019-2020. Total RNA was extracted from healthy and infected leaves using Total RNA Mini Kit (Plant) Geneaid, according to the manufacturer's instructions. The purified RNA was used as a template for the reverse transcription experiment. The degenerate Primer, NIb2F/NIb3R (Table 1), was used to detect potyviruses in the region encoding the nuclear inclusion protein $\mathrm{b}(\mathrm{NIb})$ according to Zheng et al., 2010. Positive samples were re-evaluated for the presence of SCMV by RT-PCR using specific primer pair for the SCMV coat protein gene (CP) R3/F4 (Alegria et al., 2003) during the season 2019-2020 (Table 1) in a two-step PCR. First-strand cDNA was synthesized in a reverse transcription reaction using $4 \mu \mathrm{l}$ of purified RNA, 200U of M-MLV reverse transcriptase (Fermentas, Thermo Fisher Scientific, Lithuania), $40 \mathrm{U} / \mathrm{ml}$ of RNase inhibitor, 50 pmol of antisense primer NIb3R or R3, $1 \mathrm{mM}$ dNTPs, and then incubated at $42{ }^{\circ} \mathrm{C}$ for $60 \mathrm{~min}$. The reaction mixture was inactivated by incubation at $95{ }^{\circ} \mathrm{C}$ for 3 
min. PCR was performed in a $50 \mu 1$ reaction mixture containing $5 \mu$ of cDNA, 30 pmol each of primers, $200 \mu \mathrm{M}$ dNTPs, $2 \mathrm{mM} \mathrm{MgCl}_{2}$, and $2.5 \mathrm{U}$ of Taq DNA Polymerase (GeneDirex). PCR amplification was proceeded in the thermocycler (UNO cycler). Thermo cycle condition was: Initial denaturation at $94^{\circ} \mathrm{C}$ for 3 min followed by 35 cycles of $94^{\circ} \mathrm{C}$ at $30 \mathrm{sec}, 43^{\circ} \mathrm{C}$ for NIb region $45 \mathrm{sec}$ or $66^{\circ} \mathrm{C}$ for $\mathrm{CP}$ region $30 \mathrm{sec}, 72^{\circ} \mathrm{C}$ at $1 \mathrm{~min}$ and a final extension for $10 \mathrm{~min}$ at $72^{\circ} \mathrm{C}$. The PCR products were directly analyzed as described by Sambrook et al., (1989) using Agarose Gel Electrophoresis by pre-staining 1\% agarose gel with EZView stain and visualized by UV illumination.

\section{Sequencing and phylogenetic analysis}

The identification of the virus isolate was carried out based on DNA sequencing. The PCR amplified products were purified using Geneaid PCR purification kit according to the manual protocol and submitted for DNA sequencing, using the same primers that were used for amplification, by the Analysis Company using ABI 3730xl DNA Sequencer. The obtained DNA sequences corresponding to SCMV isolate $(\mathrm{HaF})$ were deposited in the NCBI database under the acc. no. (MT739332 and MZ351729) and compared to that of other strains. Multiple sequence alignment was conducted using DNAMAM software (Lynnon Biosoft, Quebec, Canada) to obtain nucleotide and deduced amino acid identities. Phylogenetic trees were constructed using the maximum-likelihood (ML) method in the DNAMAM software

Table 1: Nucleotide sequences of primer pairs used in RT-PCR assay

\begin{tabular}{|c|c|c|c|}
\hline Gene & Primers & Primer Sequences 5'-3' & Expected size \\
\hline \multirow{2}{*}{ NIb } & Sense NIb2F & GTITGYGTIGAYGAYTTYAAYAA & \multirow{2}{*}{$350 \mathrm{bp}$} \\
\hline & Antisense NIb3R & TCIACIACIGTIGAIGGYTGNCC & \\
\hline \multirow[b]{2}{*}{$\mathbf{C P}$} & F4 & GTTTTYCACCAAGCTGGAACAGTC & \multirow{2}{*}{$900 \mathrm{bp}$} \\
\hline & R3 & AGCTGTGTGTCTCTCTGTATTCTC & \\
\hline
\end{tabular}

\section{Results}

Symptoms and Enzyme-linked immunosorbent assay (ELISA) for detecting sugarcane viruses

As shown in (Figs. 1A-C), samples collected from naturally infected sugarcane plants exhibited virus-like symptoms such as severe mosaic, chlorotic streaks, and reddish necrotic streaks, as compared to healthy leaves (Fig. 1D). The SCMV was detected in all collected samples of symptomatic leaves and of stalks by field visual inspection and I-ELISA tests, respectively.
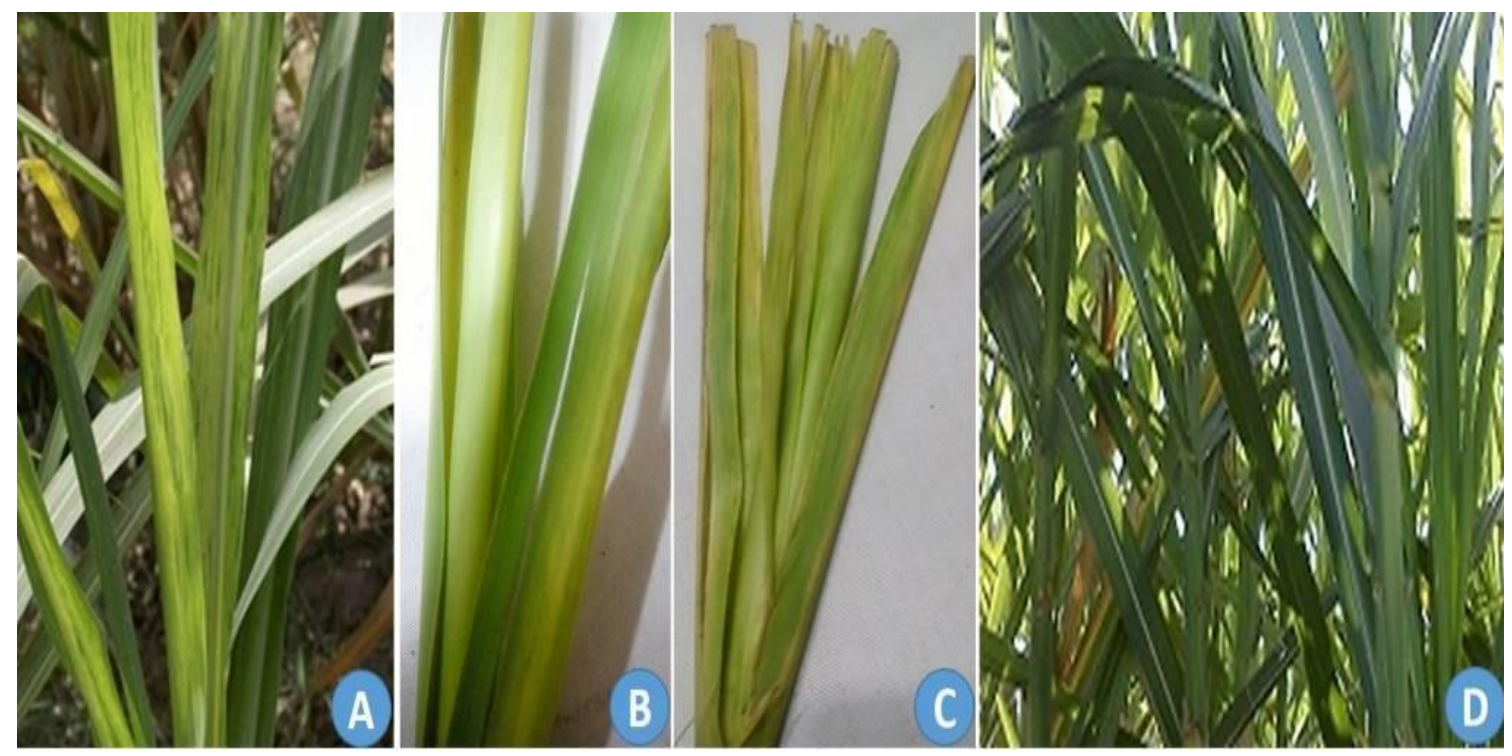

Fig. 1: Natural symptoms of SCMV infection on sugarcane plants cv. G.T. 54-9 (A) severe mosaic; (B) chlorotic streaks; (C) reddish necrotic streaks; (D) healthy sugarcane leaves. 
Effect of infection with SCMV on agronomic characteristics, and juice quality traits of sugarcane

Twelve parameters representing agronomic and yield components were measured for the healthy and infected G.T. 45-9 cultivar with SCMV during two consecutive crop cycles (Table 2 and $3)$.

Table 2: Effect of infection with SCMV on growth parameters of the commercial sugarcane variety (G.T. 54-9) at harvest seasons 2018/2019 and 2019/2020.

\begin{tabular}{lcccccc}
\hline \multirow{2}{*}{ Parameters } & \multicolumn{3}{c}{ Season 2018-2019 } & \multicolumn{3}{c}{ Season 2019-2020 } \\
\cline { 2 - 7 } & H & In & LSD 0.05\% & H & In & LSD 0.05\% \\
\hline Stalk height (cm) & 230.0 & 124.5 & 52.88 & 257.0 & 151.0 & 17.22 \\
Stalk diameter (cm) & 2.790 & 1.910 & 0.250 & 2.660 & 2.170 & 0.320 \\
No. internodes/Plant & 22.60 & 15.00 & 5.900 & 22.37 & 15.40 & 1.480 \\
Chlorophyll content & 34.06 & 14.97 & 9.050 & 31.02 & 18.63 & 2.600 \\
Cane yield (ton/fed) & 54.16 & 20.24 & 11.42 & 55.89 & 18.20 & 8.930 \\
\hline
\end{tabular}

H: Healthy plants. In: Infected plants. LSD: The Least Significant Difference

Table 3: Effect of infection with SCMV on juice quality traits of the commercial sugarcane variety (G.T. 54-9) at harvest seasons 2018/2019 and 2019/2020.

\begin{tabular}{lcccccc}
\hline \multirow{2}{*}{ Traits } & \multicolumn{3}{c}{ Season 2018-2019 } & \multicolumn{3}{c}{ Season 2019-2020 } \\
\cline { 2 - 7 } & H & In & LSD 0.05\% & H & In & LSD 0.05\% \\
\hline Bx \% & 22.69 & 22.61 & 0.06 & 23.36 & 23.22 & 0.10 \\
Sucrose \% & 19.63 & 19.15 & 0.36 & 20.14 & 17.76 & 0.57 \\
Pol \% & 14.87 & 14.70 & 0.35 & 15.22 & 14.58 & 0.30 \\
Rs \% & 1.030 & 1.130 & 0.20 & 1.070 & 1.120 & 0.65 \\
Ap \% & 94.00 & 92.10 & 0.98 & 94.50 & 82.85 & 1.96 \\
Sugar recovery \% & 13.97 & 13.50 & 0.11 & 14.36 & 11.89 & 0.34 \\
Sugar yield (ton/fed) & 7.320 & 2.480 & 3.26 & 8.030 & 2.180 & 1.38 \\
\hline
\end{tabular}

H: Healthy plants. In: Infected plants. LSD: The Least Significant Difference

An examination of both stalk height and stalk diameter data revealed a difference between diseased and healthy plants but there may have been a highly effective on stalk height (Fig. 2 A). Planting the infected sugarcane with SCMV caused in decreasing the height and diameter of canestalks by $45.8 \%$ and $31.5 \%$, respectively in the first season, corresponding to $41.2 \%$ and $18.4 \%$ in the second season, compared with that high recorded in case of planting disease-free sugarcane plant source (Table 2). The results also clear that the number of internodes per infected plant with SCMV has the same decreased percentage of approximately $31 \%$ as compared with the healthy plants in both seasons. Due to infection with SCMV, leaves of sugarcane plants displayed a yellowish-green with mosaic symptoms (Fig. 2 B) as compared to leaves in the healthy plants during grand growth phases and resulted in lower concentrations in chlorophyll content by $56 \%$, and $40 \%$ in both seasons, respectively. A similar trend was also observed with net cane yield (tons/fed) in infected plants which was also significantly decreased by $62.6 \%$ and $67.4 \%$ in the first and second season, respectively.

Besides, in both tested seasons, juice quality traits such as Bx, Sucrose, Pol, Ap, Sugar recovery, and Sugar yield have been shown to negatively change because of viral infection, as shown in Table 3. However, the Rs in the infected stalk component with SCMV significantly increased as compared to a healthy stalk component (1.03\%). In the 2018-2019 season, $1.130 \%$ of Rs was present in the infected stalk component with SCMV, while in the 2019-2020 season was $1.120 \%$. 


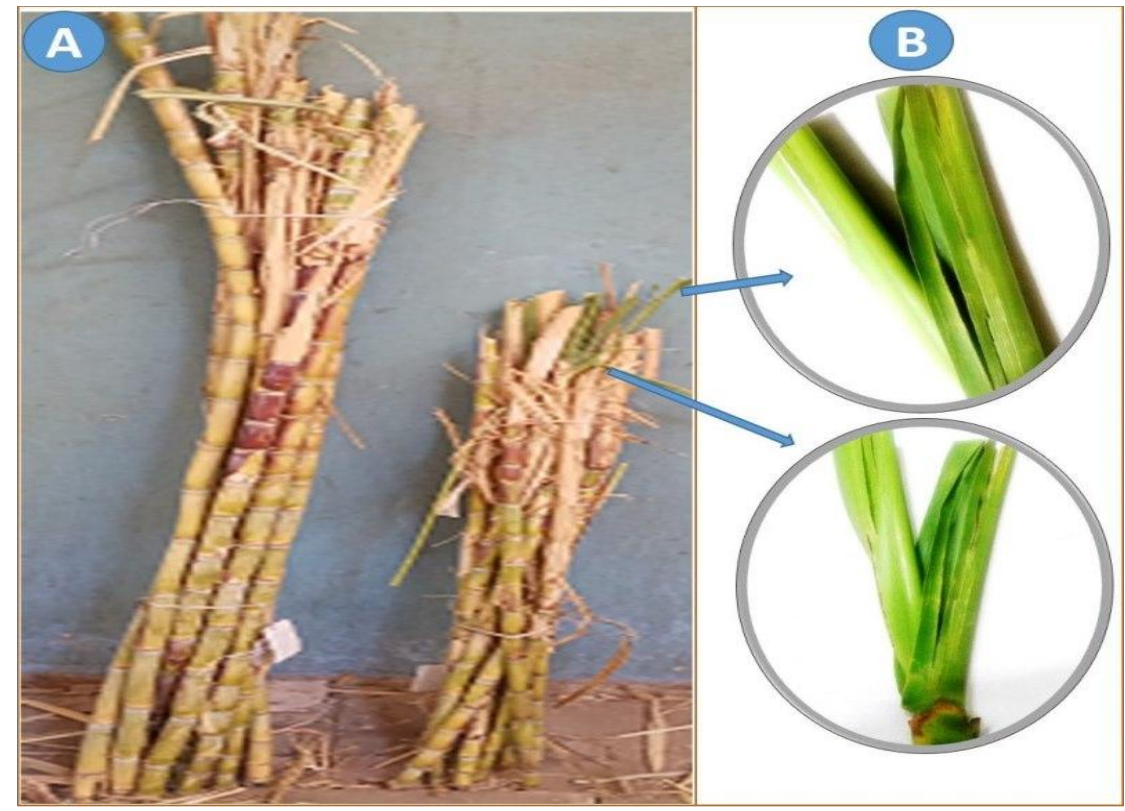

Fig. 2: Effect of infection with SCMV on growth, length $(\mathrm{cm})$ of stalks, and the number of internodes of commercial sugarcane cultivar G.T.54-9. (A) Infected sample (Right) and the corresponding healthy sample (Left). (B) Varying degrees of destruction of the chlorophyll caused by SCMV infection during grand growth phases.

\section{SCMV detection using RT-PCR}

The disease symptoms caused by SCMV are difficult to distinguish from these caused by SCSMV and SrMV due to similar symptoms and coinfection from time to time with the two viruses. At the molecular level, the SCMV was detected in ten samples originating from infected-cuttings of the commercial sugarcane variety (G.T. 54-9) using degenerate primers that detect conserved NIb region of potyvirus genomes through RT-PCR test. Similar results were obtained for the second season through the RT-PCR test using the coat protein-specific primers (F4/R3). Electrophoresis analysis of the RT-PCR product showed specific bands at $\sim 350$ bp and 900 bp representing the expected size for the amplified product for NIb and CP gene respectively when viral RNA was extracted from infected leaf sugarcane at grand growth phases in both tested seasons. Results of amplification reactions for the NIb region with the NIb2F/ NIb3R primers set are shown in Fig. 3A. Lanes from 2-10 represent data for the first tested season indicating that this set of primers also acts in a potyvirus-specific manner. The RT-PCR amplified SCMV CP gene, with the expected size of about $900 \mathrm{bp}$, from infected leaf sugarcane samples was shown in Fig. 3B. Lanes from 2-10 represent data for the second tested season). No fragments were amplified from the RNA extracted from any sample originating from the healthy cuttings (Fig.3A and B, lane 1).

\section{Nucleotide sequence identities and the phylogenetic analysis}

Two degenerate primers NIb2F/NIb3R were used to amplify the 350 bp DNA fragment isolated from sugarcane plants infected with the prospective potyvirus isolate. The amplified products of the $\mathrm{NIb}$ region of the polyprotein gene and the CP gene were analyzed by nucleotide sequence analysis. The sequence obtained from the amplified product of the NIb region was subjected to BLASTn search in GenBank. A BLASTn search in GenBank revealed that the sequence had an identity ranging from 90-95\% with Sugarcane SCMV-isolates at the nucleotide sequence level worldwide. Multiple sequence alignment and the homology tree were done along with 28 sequences of SCMV isolates available in NCBI GenBank with their accession numbers and description (Table 4) in addition to SCMV-HaF isolate in this study. The nucleotide sequence comparison of the only $304 \mathrm{bp}$ from the NIb region of Egyptian SCMV-HaF isolate revealed nucleotide identity 94.1- 95.1\% with India, South Africa, Iran, and Argentina isolate of SCMV with accession numbers KT719179.1, U84578.1, KT895080.1, and JX237867.1 respectively, as indicated in Table 4. The obtained results showed that isolates NRA and ARG-914 from Iran and Argentina had the highest homology (95.1\%) with the HaF 

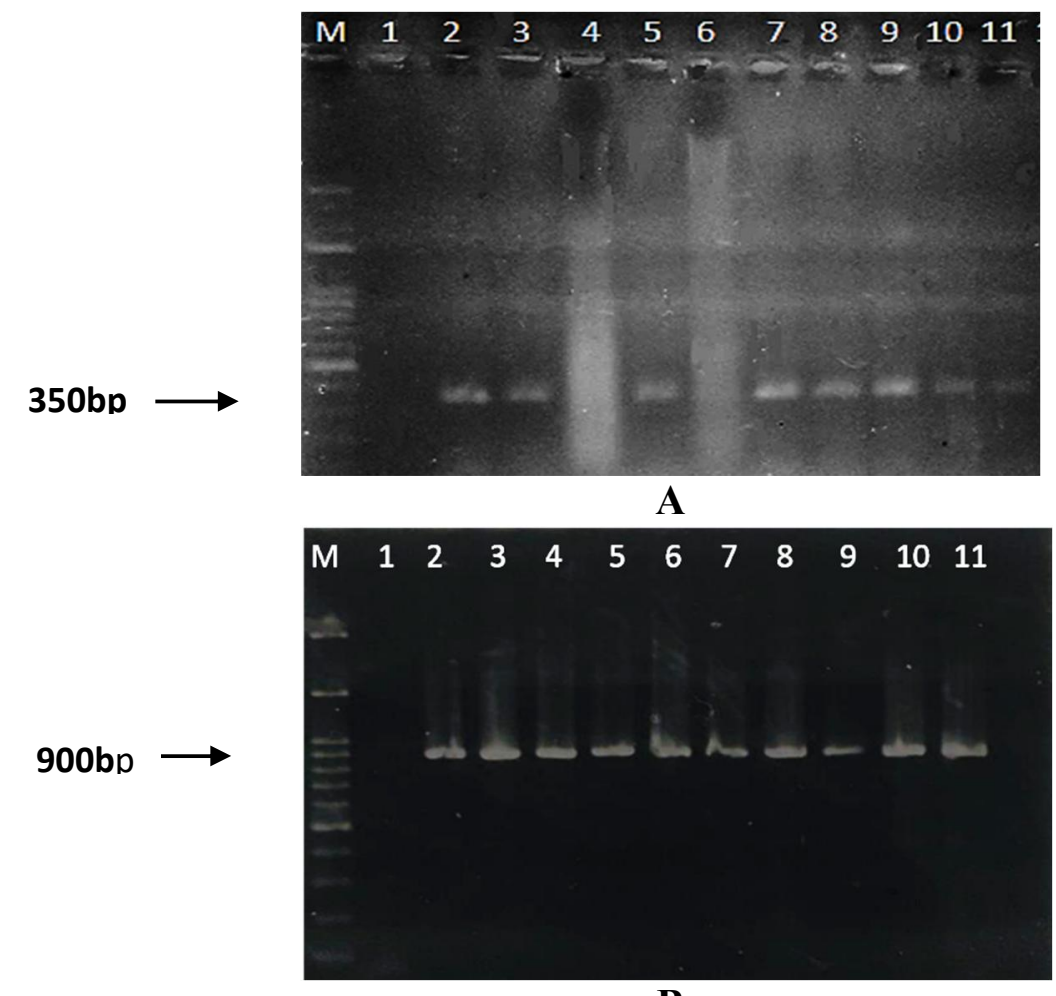

B

Fig. 3: $1 \%$ agarose gel electrophoresis analysis of the RT-PCR products from infected leaf sugarcane at grand growth phases in both tested seasons (A) in 2018-2019 using degenerate primers for potyviruses in conserved $(\mathrm{NIb})$ coding region. (B) in season 2019-2020 using (CP) coat protein gene-specific primer for the SCMV. M: 100bp DNA ladder. Lane1: Healthy Sugarcane Plant. Lanes 2 to lane 10 represent the RT-PCR amplicons from leaves of randomly sugarcane stalks in the two tested seasons.

isolate (Table 4). On the other hand, the sequence of NIb region of Egyptian SCMV-HaF isolate revealed nucleotide sequence identity ranging from 80.3-83\% with SCMV-isolates that infect maize crops grown in nine countries around the world. While it showed the lowest sequence homology (78.3\%) with SCMV-Canna isolate from China (accession No. KU561096.1) as indicated in Table 4. The nucleotide sequence comparison of $835 \mathrm{bp}$ from the coat protein gene of the Egyptian HaF isolate revealed that the $\mathrm{HaF}$ isolate shared the highest nucleotide identity (99.9\%) with the Egyptian isolate EGY7-1 with accession No. AJ491963.1; and had high sequence similarity ranged from 97.9 - 100\% with all Iranian reference isolates from sugarcane (NRA, Maz-N5, Khuz13-cp57, JGr-59, and KhuzM) as illustrated in Table 4. While the HaF-CP showed low sequence homology $76.2-82.1 \%$ with all reference SCMV isolated from Maize (Table 4) except with ZRA isolate (98.9\%) from Iran (accession No. KT895081 ). The partial nucleotide sequence of the HaF isolate coat protein gene (835bp) was subjected to the phylogenetic tree analysis.

The phylogenetic analysis showed that the HaF isolate grouped in a clade with the EGY7-1 and KhuzM isolates and it is closely related to KhuzM isolate from Iran with a bootstrap value above 900 as shown in Fig. 4. The multiple sequence alignments of deduced amino acids (aa) sequences revealed that the $835 \mathrm{bp}$ nucleotide length of the $\mathrm{HaF}$ isolate coat protein encodes a predicted 278 aa and shared 100\% similarity with the EGY7-1 (accession No. AJ491963.1) and KhuzM isolates (KX430777.1) from Egypt and Iran respectively (data not shown). In addition, the HaF isolate contains a conserved DAG motif in its coat protein N-terminal region (Fig. 5).

In an attempt to assess the serotype of the $\mathrm{HaF}$ isolate; the multiple nucleotide sequence alignment for $240 \mathrm{bp}$ core region (CR) (from nt 350 to nt 590) of the coat protein gene with (A, B, D, E, and SC-AU) SCMV serotype reference strains from USA and Australia (Yang and Mirkov 1997) 
obtained from GenBank, with accession No. U57354.1, U57355.1, U57356.1, U57357.1, and D00948.1 respectively were studied. The sequence comparison retrieved that the coat protein core region of Egyptian SCMV HaF isolate shared 100\% sequence similarity with Egyptian isolate EGY71 published in Genbank with accession AJ491963.1 [Alegria et al., (2003)] and shared 98\% sequence identity with SCMV-E strain with accession No. U57357.1 from the USA.

The phylogenetic tree relatedness for $240 \mathrm{bp}$ core region (CR) of $\mathrm{HaF}$ isolate coat protein gene with SCMV serotype strains showed that the HaF isolate clustered in a monophyletic group with the Egyptian isolate EGY7-1 and closely related to SCMV-E strain with accession No. U57357.1 (Fig. $6 \mathrm{~A}$ ). On the other hand, the sequence alignment for about $350 \mathrm{bp}$ (from nt 1 to nt 350) of Hyper Variable Region (CP-HVR) shared low sequence identity (94 - 95\%) with all SCMV strains A, E, and B, D, SC-AU respectively. The phylogenetic tree for 350 bp of Hyper Variable Region (HVR) results that the HaF isolate is outgroup and less closely related to other reference SCMV serotype isolates in the tree (Fig 6B). The partial nucleotide sequences of the present study, (304bp) of the NIb gene and $835 \mathrm{bp}$ of the CP gene of Egyptian SCMV (HaF isolate), had deposited into the GenBank under acc. no. MT739332 and no. MZ351729.

Table 4: The Accession numbers, description, and the Homology matrix of different 29 Sugarcane Mosaic Virus (SCMV) isolate available in NCBI GenBank.

\begin{tabular}{|c|c|c|c|c|c|c|c|}
\hline \multirow{2}{*}{\multicolumn{2}{|c|}{ Isolate name }} & \multirow{3}{*}{$\begin{array}{l}\begin{array}{c}\text { Accession } \\
\text { No. }\end{array} \\
\begin{array}{l}\text { The current } \\
\text { isolate }\end{array}\end{array}$} & \multirow{3}{*}{$\begin{array}{l}\text { Country } \\
\text { Egypt }\end{array}$} & \multirow{3}{*}{$\begin{array}{c}\begin{array}{c}\text { Host } \\
\text { plant }\end{array} \\
\text { Sugarcane }\end{array}$} & \multirow{3}{*}{$\begin{array}{c}\begin{array}{c}\text { The tested } \\
\text { gene }\end{array} \\
\text { NIb-CP }\end{array}$} & \multicolumn{2}{|c|}{ Homology matrix } \\
\hline & & & & & & \multirow{2}{*}{$\begin{array}{l}\text { Nib\% } \\
100\end{array}$} & \multirow{2}{*}{$\begin{array}{l}\mathbf{C P \%} \\
100\end{array}$} \\
\hline 1 & $\mathrm{HaF}$ & & & & & & \\
\hline 2 & EGY7-1 & AJ491963 & Egypt & Sugarcane & $\mathrm{CP}$ & NA & 99.9 \\
\hline 3 & NG-SC & MH795798 & Nigeria & Sugarcane & NIb-CP & 80.3 & 79.6 \\
\hline 4 & ARG-915 & JX237863 & Argentina & Sugarcane & NIb-CP & 93.8 & 92.5 \\
\hline 5 & ARG-936 & JX237870 & Argentina & Sugarcane & NIb-CP & 94.7 & 91.9 \\
\hline 6 & ARG-914 & JX237867 & Argentina & Sugarcane & NIb-CP & 95.1 & 97.1 \\
\hline 7 & INDSi776 & KT719179 & India & Sugarcane & NIb-CP & 94.4 & 94.4 \\
\hline 8 & NRA & KT895080 & Iran & Sugarcane & NIb-CP & 95.1 & 97.9 \\
\hline 9 & South Africa & U84578 & South Africa & Sugarcane & $\mathrm{NIb}$ & 94.7 & NA \\
\hline 10 & CN:HB:15 & KU171817 & China & Maize & $\mathrm{NIb}$ & 81.6 & NT \\
\hline 11 & Yunan & KU886553 & China & Maize & NIb-CP & 81.9 & 79.2 \\
\hline 12 & MA5-Tz & MF467404 & Tanzania & Maize & NIb-CP & 80.9 & 76.2 \\
\hline 13 & $\mathrm{Sp}$ & AM110759 & Spain & Maize & $\mathrm{NIb}$ & 83.9 & NT \\
\hline 14 & Seehausen & JX185303 & Germany & Maize & NIb-CP & 84.2 & 81.3 \\
\hline 15 & ANETF3S29632 & MH093718 & Ethiopia & Maize & NIb-CP & 79.9 & 80.2 \\
\hline 16 & T1F7S3 & MH093733 & Kenya & Maize & $\mathrm{NIb}$ & 80.9 & 79.6 \\
\hline 17 & Ohio & JX188385 & USA & Maize & NIb-CP & 81.9 & 80.3 \\
\hline 18 & ZRA & KT895081 & Iran & Maize & NIb-CP & 94.1 & 98.9 \\
\hline 19 & SCMV-P & LC377214 & Taiwan & Pineapple & $\mathrm{NIb}$ & 82.2 & NT \\
\hline 20 & SCMV-Canna & KU561096 & China & Canna & $\mathrm{NIb}$ & 78.3 & NA \\
\hline 21 & SCMV-VER1 & EU091075 & Mexico & Maize & NIb-CP & 82.6 & 82.1 \\
\hline 22 & usfl & AF006737 & USA & Sugarcane & $\mathrm{CP}$ & NA & 96.1 \\
\hline 23 & TUC-5A & EU196449 & Argentina & sugarcane & $\mathrm{CP}$ & NA & 96.8 \\
\hline 24 & CON12-1 & AJ491959 & Congo & sugarcane & $\mathrm{CP}$ & NA & 96.1 \\
\hline 25 & Isis 3 & AF006728 & Australia & Sugarcane & $\mathrm{CP}$ & NA & 97.9 \\
\hline 26 & JGr-59 & KX430774. & Iran & Sorghum & $\mathrm{CP}$ & NA & 99.0 \\
\hline 27 & Maz-N5 & KX430784. & Iran & Sugarcane & $\mathrm{CP}$ & NA & 98.6 \\
\hline 28 & Khuz13-cp57 & KX430775 & Iran & Sugarcane & $\mathrm{CP}$ & NA & 98.9 \\
\hline 29 & KhuzM & KX430777 & Iran & Sugarcane & $\mathrm{CP}$ & NA & 100 \\
\hline
\end{tabular}

NA: Not available. NT: not tested 


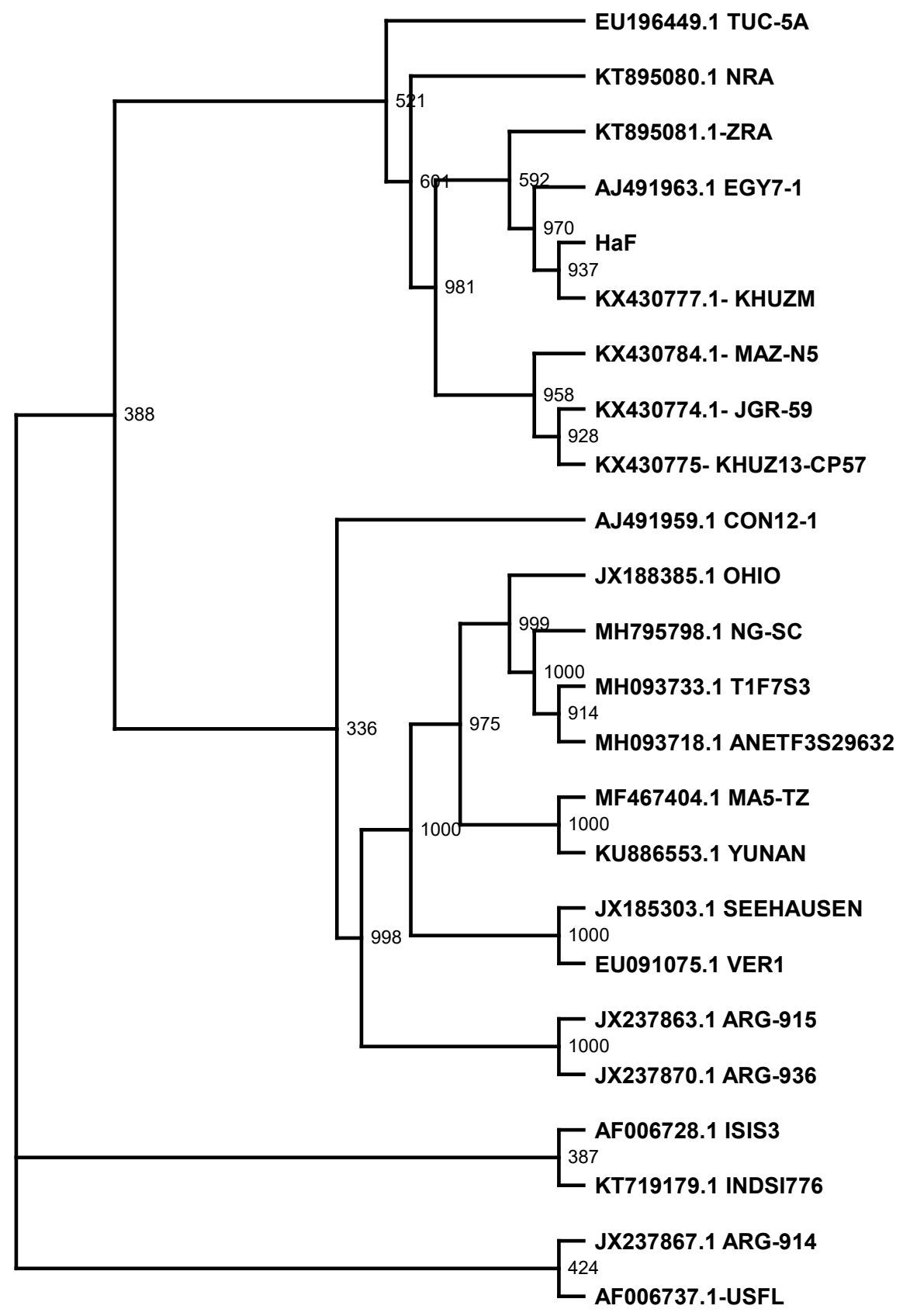

Fig. 4: The phylogenetic tree for the SCMV of the Egyptian isolate (HaF) based on coat protein (835bp) multiple sequence alignments with 23 SCMV-isolates available in GenBank using DNAMAN software. Numbers at each node indicate bootstrap value based on 1000 replications.

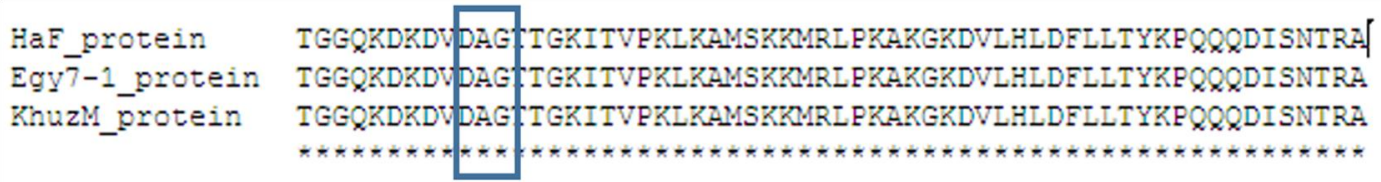

Fig. 5: The deduced amino acid sequence comparison in the N-terminal region of isolate Haf coat protein with the EGY7-1 and KhuzM reference isolates, the boxed area illustrates the Aphid transmission responsible DAG motif. 


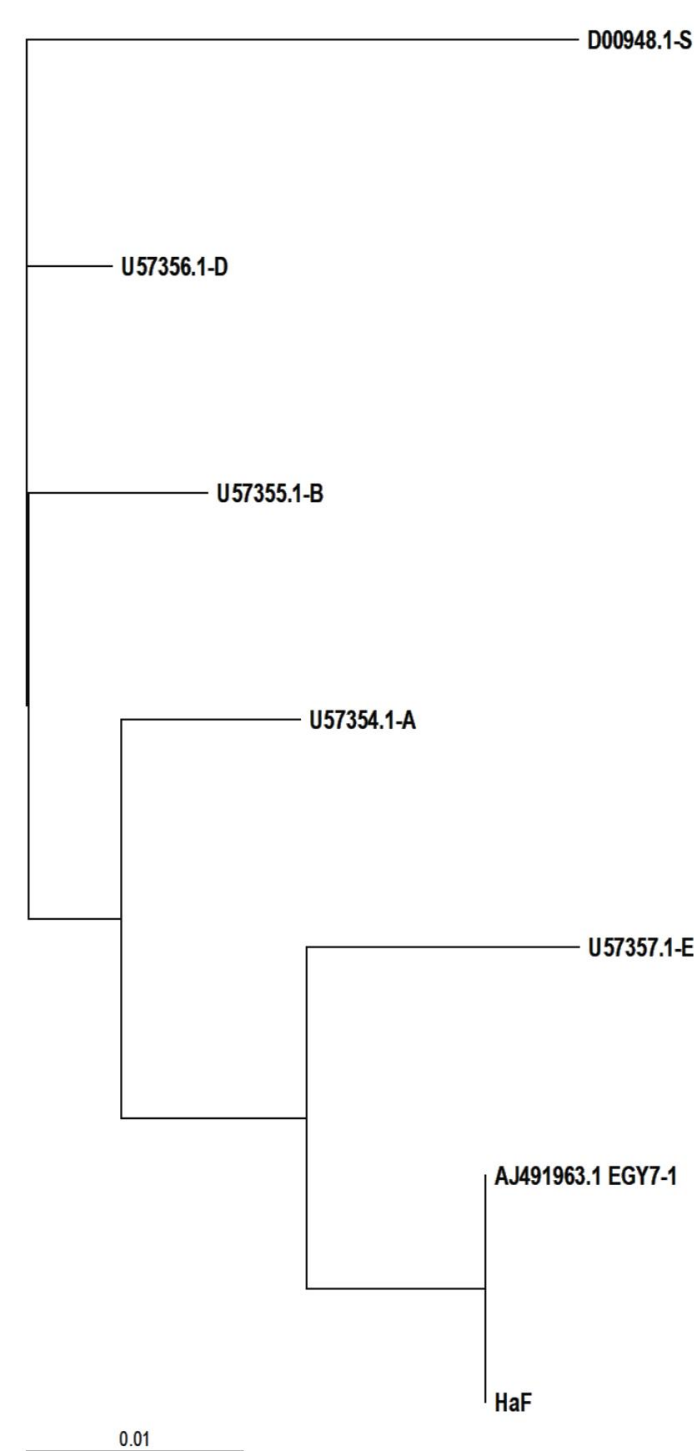

A

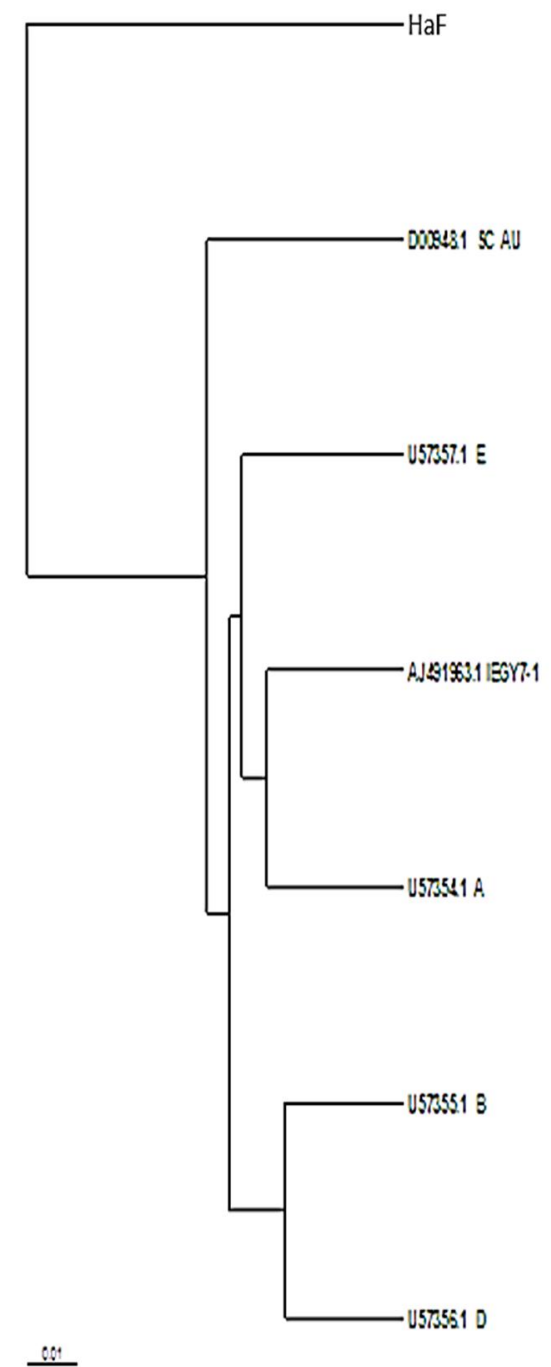

B

Fig. 6: The phylogenetic tree for the SCMV of the Egyptian isolate (HaF) based on the multiple sequence alignments with SCMV serotype strains available in GenBank. A: The phylogenetic tree of $240 \mathrm{bp}$ Core Region (CR) of HaF coat protein (CP) gene. B: The phylogenetic tree for 350 bp of Hyper Variable Region (HVR) of the CP gene relatedness with SCMV type strains.

\section{Discussion}

In Egypt, previously, a mosaic disease on sugarcane has been reported from Sabahia, Hawamdieh, Abo-Korkas, Nag-Hammadi, and Kom-Ombo experimental stations, with a typical symptom resembling that of Sugarcane mosaic virus, SCMV (Abd El Fattah et al., 2005). Reverse transcription-polymerase chain reaction (RT-PCR) based methods enable fast, accurate and detection of a potyvirus and its identity. The disease symptoms caused by SCMV are difficult to distinguish from these caused by SCSMV and SrMV due to similar symptoms and coinfection from time to time with the two viruses. RT-PCR using NIb-degenerate primers for potyviruses and ELISA technique was used to detect the causative viral agent of the mosaic disease on sugarcane; however, these methods it does not effectively distinguish between causative pathogens. The present study describes the detection and identification of the SCMV infecting Saccharum officinarum, through RT-PCR and DNA sequencing of the partial polyprotein gene including the NIb and CP regions. Total RNA was extracted from the collected sugarcane leaves, from Qena governorate, Upper Egypt showing mosaic symptoms. RT-PCR reaction was conducted to amplify the SCMV using two sets of primers $\mathrm{NIb} 2 \mathrm{~F} / \mathrm{NIb} 3 \mathrm{R}$ and R3/F4 developed to detect potyvirus species at NIb region (Zheng et al., 2010) and SCMV coat protein gene (Alegria et al., 2003). The symptomatic samples at grand growth phases in 
the two tested seasons in the present study showed a particular cDNA fragment amplified at the expected size of $\sim 350 \mathrm{bp}$ for NIb region according to Zheng et al., (2010) and $~ 900 \mathrm{bp}$ for the SCMV coat protein (CP) gene according to Alegria et al., (2003). The amplified RT-PCR product was purified and then sequenced to confirm virus isolate identification. The partial NIb sequence from samples in the 2019-2020 tested season was closest to that of the Argentinian and Iranian sugarcane strain of SCMV (ARG-914 and NRA) with an identity of 95.1\% with accession numbers JX237867 and KT895080, respectively. It is worth noting that the NIb-primers detected 40 virus isolates representing 23 known potyvirus species and several potentially new species (Zheng et al., 2010). Similar results were obtained for the second season 2019-2020 through RT-PCR test using the SCMV coat protein-specific primers (F4/R3) Alegria et al., (2003).

Such results suggest that SCMV is a common causative agent of mosaic in sugarcane in Upper Egypt. Hence the coat protein gene showed the highest nucleotide identities $97.9-100 \%$ with the Egyptian isolate and all Iranian reference isolates available in GenBank regardless of the host type either sugarcane or Maize. The highest similarity (99.9-100\%) was with isolates EGY7-1 and KhuzM at both the nucleotide and amino acid levels. Our results are consistent with Moradi et al., (2017) results. Moradi et al., (2017), stated that the Iranian isolates shared nucleotide identities of $75.5 \%-$ 99.9\% with those of other SCMV isolates available in GenBank, the highest with the Egyptian isolate EGY7-1 (97.5-99.9\%). The amino acids sequence comparison indicated that the HaF isolate contains a conserved DAG motif in its $\mathrm{N}$-terminal region in $\mathrm{CP}$ sequence which is associated with aphid transmissibility according to Atreya et al., (1991).

The phylogenetic relationships for the coat protein gene of HaF isolate among 23 SCMV isolates were constructed and the results were consistent with the nucleotide identities and the $\mathrm{HaF}$ isolate closely related to KhuzM isolate from Iran and had a common ancestor. Mahmoud and Hamed (2019) stated that the CP conserved sequence of SCMV-Egy isolate showed $97.5-99.5 \%$ and $97.5 \%$ of nucleotide and amino acid sequence similarity respectively and the highest similarity was with Iranian and Brazilian isolates. According to Alegria et al., (2003) mentioned that 86 virus isolates are clustered into five groups (A to E) especially given host origins. Hence, each SCMV type strain from sugarcane (A, B, D, E, and SC) was distributed among the phylogenetic group or subgroups. On the other hand, the population of SCMV from sugarcane in Africa including Egypt contains virus genotypes that have not yet been described. Shukla et al., (1992; 1994) and Viswanathan et al., (2009) suggested that the $\mathrm{CR}$ of $\mathrm{CP}$ is the best marker for studying the sequence relationships between virus strains in the potyvirus group.

Therefore, the phylogenetic tree for the hypervariable region (HVR) and the Core region of the SCMV-HaF coat protein gene was conducted. Since HVR of the coat protein gene is exposed at the surface, it has close contact with insect vector environments and plant systems that need frequent evolutionary changes to counteract the selection pressure being pushed on it, thereby, the HVR generates a lot of variations by undergoing addition or deletion mutations [Shukla et al., (1994), Viswanathan et al (2009)]. Thus, in our study, the multiple nucleotide sequence alignment for 240bp core region (CR) and 350 bp hyper Variable region (HVR) of the HaF coat protein with (A, B, D, E, and SC) SCMV type reference strains (Yang and Mirkov 1997) obtained from GenBank retrieved that the CR of the HaF-isolate shared $97.9 \%$ sequence homology with SCMV-E serotype strain with accession No. U57357.1 from the USA. In Addition, the coat protein conserved sequence (CR) of the SCMV (HaF isolate) showed nucleotide identity 100\% with Egyptian isolates EGY 7-1. Phylogenetic tree analysis for $240 \mathrm{bp}$ core region (CR) of the HaF isolate coat protein is closely related with SCMV$\mathrm{E}$ type strain. However, the sequence alignment for $350 \mathrm{bp}$ CP-HVR shared sequence homology (9495\%) with all SCMV type strains (A, B, D, E, and SC) and the results are not reliable as the CR (Core region). These results are in agreement with Viswanathan et al., 2009 conclusion that the genetic analysis performed with HVR is not very reliable for Core Region (CR). Our present results are inconsistent with Koike and Gillaspie (1989) who reported that three mosaic strains were reported to occur in sugarcane growing areas in Africa, including strain D in Egypt.

A natural field experiment was conducted during two consecutive seasons (2018-2019 and 2019-2020) to evaluate the impact of the SCMV infection on sugarcane production and juice quality. After eleven months from planting, various growth parameters and juice quality traits of the commercial sugarcane variety (G.T. 54-9) were determined. The obtained results during the two years (Table 2) reveal that the physiological and yield parameters were significantly reduced in 
symptomatic plants of sugarcane due to infection with SCMV. The results of this study were similar to those reported by Viswanathan and Balamuralikrishnan (2005) and Gonçalves et al., (2012). These authors found that at harvest, cane stalks taken from virus-infected plots recorded a significant reduction in cane diameter, height, and the number of internodes. Singh et al., (1997) also stated that SCMV causes major problems in most of the sugarcane growing countries and many varieties have gone out of cultivation due to yield losses of up to 50 per cent. In the present study, the viral infection caused varying degrees of destruction of the chlorophyll and a decrease of the photosynthetic rate, eventually leading to mosaic and chlorotic symptoms. Bagyalakshmi et al., (2019) stated that the severity of mosaic infection turned the green leaves to yellow blotches because of a drastic reduction in chlorophyll synthesis rate in the symptomatic plants. Srivastava et al., (2010) also stated that the chlorophyll content in the symptomatic plants is not synthesized at the same rate as in asymptomatic plants. Viswanathan and Balamuralikrishnan (2005) showed that the infection with SCMV reduced the net $\mathrm{CO}_{2}$ assimilation rate during the grand growth period as well as affected chlorophyll, $\mathrm{CO}_{2}$ fixation, the carboxylation enzymes, and sucrose metabolism in sugarcane. The analysis of chlorophyll content is important for evaluating the integrity of the inner system during the photosynthetic process within a leaf (Rong-hua et al., 2006; Jiang et al., 2010; Xu et al., 2015). Generally, many authors (Irvine, 1971; Bhargava et al., 1971) support the significant reduction in chlorophyll content due to infection with SCMV.

A similar trend was also observed under pathogen stress with several juice components of sugarcane and sugar yield except for the Rs that were increased in infected plants compared with healthy ones in both seasons. Viswanathan and Balamuralikrishnan (2005) found that, at harvest, cane stalks from virus-infected plots recorded a significant reduction in juice quality parameters. This significant effect on the quality parameters of the sugarcane juice may be due to differences in growth, decreased chlorophyll a or $b$, and mainly pathological processes. These suggestions agree with that proposed by many authors (Cook and Scott, 1995; Ayman, 2000). However, many authors confirmed that the reduction in cane juice quality, Brix, sucrose content, Ap, Pol, and sugar recovery varied according to the level of the severity of SCMV infection (Gonçalves et al., 2012; Viswanathan, 2016; Addy et al., 2017).

Concerning the Rs, the concentration increased in infected sugarcane plants with SCMV in both tested seasons by $9.7 \%$ and $4.7 \%$, respectively. The accumulation of Rs suggests the effect of the SCMV on the content of starch eventually leading to alter the carbohydrate metabolism. An earlier study (Tecsi et al., 1994b) indicated an increase in Rs and a reduction in starch content due to viral infection-induced higher starch hydrolase and lower ADP-glucose (Glc) pyrophosphorylase (AGPase). The inhibition of starch accumulation and/or starch degradation is probably due to the increased demand for soluble sugars (mainly Glc) required to maintain the high respiration rate under stress (Xiao et al., 2017). In addition, according to Pereira et al., (2017), there is a close relationship between the apparent percentage of total soluble solids (TSS) and sucrose content in the solution, and sugarcane is considered mature with high TSS or Bx concentration, among other factors. Unripe sugarcane has a high content of reducing sugars and flavour precursors compounds, which reduce Pol values resulting in the juice of dark colour and unfavourable aroma (Pereira et al., 2017). The quality indexes of sugarcane juice (Ap, Pol, TSS, or Bx) of the infected commercial sugarcane variety (G.T. 54-9) lower than the healthy ones, were evidenced in this work thus, the quality of sugarcane juice will become very poor or undesirable (Xiao et al., 2017).

\section{Conclusion}

In the present study, the RT-PCR and subsequent sequence analysis of amplified NIb and CP genomic regions have been used for rapid detection and identification of SCMV and it appeared to be the most suitable method for the identification of viruses that could be occurring in mixed infections. The multiple sequence alignment for the coat protein-core region (CP-CR) of the Egyptian SCMV$\mathrm{HaF}$ isolate showed that the Egyptian isolate is closely related to the SCMV-E serotype strain from the USA. The analysis of the quality indexes of sugarcane juice plays a vital role in the process of refining sugarcane and production management in which the most important five criteria are Pol, Ap, $\mathrm{Bx}$, Rs, and sugar-percentage of the cane juice; besides spectroscopic method has been used to measure the sugarcane quality parameters. 


\section{References}

Abd El Fattah, A.I., H.A. Nour El-Din, A.M. Abodoah and A.S. Sadik, 2005. Occurrence of two sugarcane mosaic potyvirus strains in sugarcane. Pak. J. Biotechnol., 2(1-2): 1-12.

Abd El Fattah, A.I., A.S. Sadik, A.I. Abdel-Hamid, M.A. El-Kholy and M.A. Madkour, 2004. Identification of Sugarcane mosaic potyvirus in Egypt. Egypt. J. Virol., 1(1):195-214.

Addy, H.S., N. Darsono, A.H.S. Wahyudi, A. Sholeh, C. Anugrah, F.E.S. Iriyanto, W. Darmanto and B. Sugiharto, 2017. Detection and Response of Sugarcane against the Infection of Sugarcane Mosaic Virus (SCMV) in Indonesia. Agronomy, 7, 50:1-11. doi:10.3390/agronomy7030050.

Ahmed, Z.A., A.M. Ahmed and K.S. EL-Soghier, 2014. Evaluation of three sugarcane varieties grown under different number of irrigations. Egypt. J. Agric. Res., 92 (2): 765-778.

Alegria O. M., M. Royer, M. Bousalem, M. Chatenet, M. Peterschmitt, J-C. Girard and P. Rott, 2003. Genetic diversity in the coat protein coding region of eighty-six sugarcane mosaic virus isolates from eight countries, particularly from Cameroon and Congo. Arch. Virol., 148: 357372.

AOAC, 1995. Association of official analytical chemists. Official methods of analysis, (16th Ed.), Int., Washington, DC, USA.

Atreya, P.L., C.D. Atreya and T.P. Pirone, 1991. Amino acid substitutions in the coat protein result in loss of insect transmissibility of a plant virus. Proc. Natl Acad. Sci. USA, 88:7887-7891.

Bagyalakshmi, K., R. Viswanathan and V. Ravichandran, 2019. Impact of the viruses associated with mosaic and yellow leaf disease on varietal degeneration in sugarcane. Phytoparasitica., 47:591-604.

Boddey, R.M., L.H.B. Soares, B.J.R. Alves and S. Urquiaga, 2008. Bio-ethanol production in Brazil. Pp. 321-356 in Pimentel, D. (ed.), Biofuels, solar, and wind as renewable energy systems: Benefits and risks. Springer.

Chung, B.Y.W., W.A. Miller, J.F. Atkins and A.E. Firth, 2008. An overlapping essential gene in the Potyviridae. Proc. Natl. Acad. Sci. USA, 105:5897-5902.

Clark, M.F. and A.N. Adams, 1977. Characteristics of the microplate method of enzyme linked immunosorbent assay for the detection of plant viruses. J. Gen. Virol., 34:475-483.

Cook, D.A. and K.R. Scortt, 1995. The sugar beet crop. Chapman and Hall Publisher, New York, London, Paris, 657pp.

El-Sogheir, K.S. and A.I. Abd El-Fattah, 2009. Evaluation of some promising sugar cane varieties under different row spacing. J. Biol. Chem. Environ Sci., 4(1): 285-318.

FAOSTAT, 2019. The data set "Sugarcane, production quantity (Tons)", and Area harvested (Hectare), for Egypt contains data from the year 1961 until 2018. http://www.fao.org/faostat/en/?\#data/QC.

Freed, R., S.P. Eisensmith, S. Goetz, D. Reicosky and V.W. Smail, 1989. Users Guide to MSTAT-C. Dept. of Crop and Soil Sciences and Dept. of Agricultural Economics. Michigan State University.

Gao, B., X.W. Cui, X.D. Li, C.Q. Zhang and H.Q. Miao, 2011. Complete genomic sequence analysis of a highly virulent isolate revealed a novel strain of Sugarcane mosaic virus. Virus Genes, 43:390-397.

Gomez, K.A. and A.A. Gomez, 1984. Statistical procedures for agricultural research. John Wiley, New York, 680 .

Gonçalves, M.C., L.R. Pinto, S.C. Souza and M.G.A. Landell, 2012. Virus Diseases of Sugarcane. A Constant Challenge to Sugarcane Breeding in Brazil. Funct. Plant Sci. Biotechnol., 6(2):108116.

Ismail, A.M.A., M.A. Bekheet and A.S. Abo El-Hamd, 2008. Yield and quality of four sugarcane varieties as influenced by seed rate and nitrogen fertilization. Egypt. J. Appl. Sci., 23(1):107123.

Jiang, J.B., Y.H. Chen and W.J. Huang, 2010. Using hyperspectral remote sensing to estimate canopy chlorophyll density of wheat under yellow rust stress. Spectrosc. Spect. Anal., 30(8):22432247.

Koenig, R.C. and H.L. Paul, 1982. Detection and differentiation of plant viruses by various ELISA procedures. Acta Hort., 127:147-158. 
Koike, H. and A.G.Jr. Gillaspie, 1989. Mosaic', In Ricaud, C. Egan, B.T., A.G.Jr. Gillaspie and C.G. Hughes, (eds.). Diseases of Sugarcane New York, USA: Elsevier, 301-322.

Langeveld, S.A., J.M. Dore, J. Memelink, A.F. Derks, C.I. van der Vlugt, C.J. Asjes and J.F. Bol, 1991. Identification of potyviruses using the polymerase chain reaction with degenerate primers. J. Gen. Virol., 72:1531-1541.

Mahmoud, A. and A. Hamed, 2019. In Silico epitope prediction of coat protein gene of Sugarcane Mosaic Virus. Egypt. J. Genet. Cytol., 48:235-243.

Moradi, Z., E. Nazifi and M. Mehrvar, 2017. Occurrence and Evolutionary Analysis of Coat Protein Gene Sequences of Iranian Isolates of Sugarcane mosaic virus. Plant Pathol. J., 33:296-306.

Pereira, L.F.M., V.M. Ferreira, N.G. De Oliveira, P.L.V.S. Sarmento, L. Endres and I. Teodoro, 2017. Sugars levels of four sugarcane genotypes in different stem portions during the maturation phase. Annals of the Brazil. Acad. Sci., 89(2):1231-1242.

Plews, R.W. (ed), 1970. Analytical Methods used in Sugar Refining. Elsevier Publishing Co, Amsterdam, 162-164.

Rao, G.R., M. Chatenet, J.C. Girard and P. Rott, 2006. Distribution of Sugarcane mosaic and Sugarcane streak mosaic virus in India. Sugar Tech., 8:79-81.

Rong-hua, L.I., P.G. Guo, B. Michael, G. Stefania and C. Salvatore, 2006. Evaluation of chlorophyll content and fluorescence parameters as indicators of drought tolerance in barley. Agric. Sci. China, 5:751-757.

Shukla, D.D., R. Lauricella and C.W. Ward, 1992. Serology of potyviruses: current problems and some solutions. In: Barnett, O.W. (eds) Potyvirus Taxonomy. Archives of Virology (Supplementum 5), vol 5. Springer, Vienna.

Shukla D.D., C.W. Ward and A.A. Brunt, 1994. The Potyviridae (CAB International, Cambridge University Press, Cambridge), 516.

Singh, S.P., G.P. Rao, J. Singh and S.B. Singh, 1997. Effect of Sugarcane mosaic potyvirus infection on metabolic activity, yield and juice quality. Sugar Cane, 5:19-23.

Tang, W., Z.Y., Yan, T.S. Zhu, X.J. Xu, X.D. Li and Y.P. Tian, 2018. The complete genomic sequence of Sugarcane mosaic virus from Canna spp. in China. Virol. J., 15:147.

Tecsi, L.I., A.J. Maule, A.M. Smith and R.C. Leegood, 1994. Metabolic alterations in cotyledons of Cucurbita pepo infected by Cucumber mosaic virus. J. Exp. Bot. 45:1541-1551.

Viswanathan, R. and M. Balamuralikrishnan, 2005. Impact of Mosaic Infection on Growth and Yield of Sugarcane. Sugar Tech., (1): 61-65.

Viswanathan, R. R. Karuppaiah and M. Balamuralikrishnan, 2009. Identification of new variants of SCMV causing sugarcane mosaic in India and assessing their genetic diversity in relation to SCMV type strains. Virus Genes, 39:375-386.

Xiao, Z., X. Liao and S. Guo, 2017. Analysis of sugarcane juice quality indexes. J. Food Quality, vol. 2017, Article ID 1746982, 6 pages. https://doi.org/10.1155/2017/1746982.

Xu, D.Y., X.J. Li, Y.Q. Dou, M.Q. Liu, Y.H. Yang and J.J. Niu, 2015. Estimation of the chlorophyll contents of tobacco infected by the mosaic virus based on canopy hyperspectral characteristics J. Anim. Plant Sci. 25 (3 Suppl. 1):158-164.

Yadav, R.L. and R.K. Sharma, 1980. Effect of nitrogen levels and harvesting dates on quality traits and yield of four sugarcane genotypes. Indian Sugar Cane J., 50(7): 581-589.

Yahaya, A., D.B. Dangora, A.U. Khan and M.A. Zangoma, 2014. Detection of Sugarcane mosaic disease (SCMV) in crops and weeds associated with sugarcane fields in Makarfi and Sabon Gari local government areas of Kaduna state, Nigeria. Int. J. Curr. Sci., 11: 99-104.

Yang, Z.N. and T.E. Mirkov, 1997. Sequence and Relationships of Sugarcane Mosaic and Sorghum Mosaic Virus Strains and Development of RT-PCR-Based RFLPs for Strain Discrimination, Phytopathol., 87: 932-939.

Zheng, L., B.C. Rodoni, M.J. Gibbs and A.J. Gibbs, 2010. A novel pair of universal primers for the detection of potyviruses. Plant Pathol., 59:211-220. 